\title{
Transformation of Scientific Research Into Teaching-A Case of Enzymatic Mechanism and Kinetics
}

\author{
Fangdi Cong ${ }^{1,2}$, Xiaohong Wang ${ }^{1}$, Ping $\mathrm{Li}^{1} \&$ Shulin Zhang ${ }^{2}$ \\ ${ }^{1}$ Department of Biopharmaceuticals, College of Basic Science, Tianjin Agricultural University, Tianjin, China \\ ${ }^{2}$ Tianjin Key Laboratory of Aqua-ecology and Aquaculture, Tianjin Agriculture University, Tianjin, China \\ Correspondence: Fangdi Cong, College of Basic Science, Tianjin Agricultural University, ON. 22, Jinjing Road, \\ Tianjin, China.
}

Received: June 16, 2018

doi:10.20849/aes.v3i3.449
Accepted: August 13, 2018

Online Published: August 14, 2018

URL: https://doi.org/10.20849/aes.v3i3.449

\begin{abstract}
It is one of main tasks in university teaching to solve the contradiction between scientific research and teaching, so as to return the present teaching work to the essence of university education, effectively imparting the professional knowledge and technical ability to undergraduates. An effective strategy for solving this problem is to carry out teaching work by the transformation of scientific research into teaching. That is to say, the scientific research results obtained by teachers are integrated into course teaching, or students are guided into the scientific research activities undertaken by teachers in some way. Here taking the teaching content of enzymatic mechanism and kinetics in biochemistry, one teaching knowledge point with great difficulty, as an example, the paper expounds the teaching idea, selecting content, designing plan and completing effect by the method of scientific research into teaching. It is minded to be taken as a useful case referred by university teacher at work to implement the transformation of scientific research into teaching, so as to improve the teaching effect of courses, especially those important, in universities.
\end{abstract}

Keywords: scientific research, teaching, biochemistry, enzyme catalysis mechanism

\section{Introduction}

\subsection{Problem in University Teaching and Strategy}

In university teaching, there is a widespread phenomenon of teachers' emphasis on scientific research and disregard of teaching, which seriously affects the decline of teaching quality and lead to the increase of students failed in course examination, which goes against the task training on them (Chen, 2016). In order to return to the essence of university teaching, the idea of transforming scientific research into teaching is put forward, and the scientific research promoting teaching is in accordance with the educational thought linking theory with practice, which is an important way to improve the quality of teaching in colleges and universities. Because the teaching contents can be enriched and reformed by scientific research findings (Yan \& Zhang, 2015). Many university teachers have begun the investigation on transformation of scientific research into teaching and actively engaged in related work (Wang, Zhao, Wang \& Xu, 2017), and achieved some encouraging results (Wei, Jiang \& Liu, 2017). The transformation of scientific research into teaching can overcome the disadvantages of traditional teaching, avoid simple knowledge inheritance, enhance the ability to use knowledge, cultivate students' scientific research quality, train students' creative thinking ability, and establish a new learning atmosphere for undergraduates $(\mathrm{Wu}, \mathrm{Li} \& \mathrm{Lu}, 2017)$. The advantages of scientific research into teaching are not only deeply realized by us, but also this new practice teaching mode has been put into practice here. In this case, the teaching of enzyme catalysis and kinetics in biochemistry was taken as an example to demonstrate the idea and method of scientific research into teaching, as well as the corresponding teaching effect.

\subsection{Teaching Idea of Scientific Research Into Teaching}

The scientific research into teaching actually is a way that linking theory with practice, which also is an effective route to solve the difficulty existed in some courses. Through the experiment, practice and especially the scientific research activities, the participants can witness the content include in the scientific theory and effectively improve the effectiveness of teaching (Guo, Xu \& Zhang, 2017). The idea of combining theory with practice is adapted to the teaching and cognitive fields of various subject courses, especially for the contents being abstract, complex and 
difficult to be visually seen. For that it is very difficult to understand those abstract theory, complex structure and change mechanism only by text introducing and figure illustrating in book (Yu \& Chen, 2017). Here, scientific research into teaching, that is to verify knowledge through experimental research, and find new evidence and more in-depth cognize knowledge through scientific innovations. The approach not only can effectively consolidate the studied theoretical knowledge, but also can benefit them to encounter new discoveries and improve their scientific quality and ability. It can be seen that it is very useful for scientific research into teaching, a model of theory combined with practice.

\subsection{Selecting Teaching Content in Biochemistry}

Biochemistry, considered by teachers, is a course more difficult than others. For example, 'enzyme chemistry' is an important and representative chapter. The essence of enzyme is protein macromolecule with complex structure, and the mechanism and kinetics of enzyme catalysis are the key and difficult points of this chapter. It is hard for students to understand this part of content, for instance the unusual catalytic effects of enzymes and the tunable properties of their catalytic activities, only by theoretical teaching and illustration (Zhao et al, 2016). And thus it is very necessary to study and experience the catalytic properties of enzymes through experiments, especially scientific research activities, which help to promote students' learning initiative and also are conducive in cognizing and understanding knowledge in other chapters. Therefore, in biochemistry teaching, with the support of scientific research projects, we encourage students to actively participate in scientific research work, courageously apply undergraduates' innovative entrepreneurship projects, forwardly combine research activity with their graduation thesis, and timely write research results into scientific papers and publish them. In this way, the scientific research methods of enzyme catalytic mechanism and kinetics in the teacher' project are introduced into biochemical teaching, effectively improving teaching results, and cultivating students' qualities of active learning, scientific thinking, and innovation ability, etc. Gradually the number of students participating in project is increased and their participation effect is enhanced,

\section{Method}

\subsection{Transformation Idea}

This case intends to introduce the "scientific research method of enzyme chemistry" into teaching. The research of enzyme chemistry is mainly to study the mechanism and kinetics of enzyme catalysis. The research method is mainly to rely on instrumental analysis and reaction kinetics, to study the conformation changes, activity and stability of enzymes. Taking lipase as an example, by participating in the research activities of scientific research project, students strengthen their understanding on the catalytic mechanism and kinetics of enzymes in biochemical courses, by employing scientific research to verify the tunability of enzymatic activity, the denaturation of enzyme protein in organic solvents, the interface activation mechanism of lipase, and the stability of immobilized enzyme, etc. And also in researches, the operation on gas chromatography, liquid chromatography and infrared chromatography instruments, and the use on origin software, all are good for students to understand biochemical courses, and therefore cultivate scientific research quality and innovative thinking ability.

\subsection{Transformation Design}

The problem to be solved by teaching is the difficulty in biochemical course: enzyme catalysis mechanism and kinetics. To solve this problem, students are guided to participate in related enzymatic scientific research projects, such as 'Research on the enzymatic synthesis and disease-resistance effects of fish vitamin C esters' carried in our lab. The basic research part of the project is to improve the stability and catalytic activity of lipases by means of enzyme immobilization, which is exactly related to the teaching content "enzymatic catalysis mechanism and kinetics", being the core part of the chapter of enzyme chemistry in the biochemistry course. It is convenient to guide some students to participate in the research of this project. Through the study of enzyme immobilization and specifically experimental research on enzymatic synthesis, they experienced knowing enzyme conformation, stability, and activity-regulatory effects, which helped students to deepen understanding and mastery of biochemical courses, and strengthen learning interest, innovative thinking ability and scientific research quality.

\subsection{Transformation Methods}

The researched enzymes are Pseudomonas cepacia lipase, Pseudomonas fluorescens lipase and Aspergillus niger lipase, which can be purchased from market. For these lipases, they behave excellent catalytic activity at the interface of water and oil (organic phase), which is the basic theory for catalysis of them, called the interface activation mechanism. Based on the theory, hydrophilic macromolecules, e.g., carboxymethyl cellulose (CMC), acrylic resin and absorbent cotton were used to replace water molecules on the water/oil interface to stabilize the enzyme protein. By immobilization, immobilized lipases are prepared and used to catalyze the transesterification 
of vinyl acetate and alcohol, and to synthesize useful odors such as hexyl acetate, cinnamyl acetate and decyl acetate, and ascorbic acid fatty acid ester. Comparing conformation and kinetic properties of immobilized and native enzymes, it was found the changes of enzyme conformation, the tunability of catalytic activity, and the impacts of substrate, solvent, and temperature on enzyme catalysis, so as to understand the catalytic mechanism and kinetics of these lipases.

\subsection{Transformation Examples}

By studying the immobilization and stability of enzymes, students' understanding on the mechanism of enzyme catalysis was enhanced. The catalytic mechanism was closely connected with the enzyme conformation. In the case of lipase, it has excellent catalytic activity at the water/oil interface. At the interface, on the one hand, the aqueous phase can optimize the enzyme to maintain the stable dominant conformation; on the other hand, there is a "lid" structure over the active site of the enzyme, a two pro alpha helix, closed in the water phase. In the oil (organic) phase, the lid opens and allows the substrate molecules to enter the active site. Lipase showed excellent catalytic activity at the water/oil interface. Considered condition in favor of synthetic ester, it is better for synthetic reactions in pure organic phase, but the enzyme is inclined to be degenerated and deactivated by organic solvents. In research, the hydrophilic macromolecules instead of water was used to stabilize enzyme protein molecules and prevent them denaturated to improve enzyme catalytic effect, so as to benefit understanding on mechanism of enzyme catalysis.

The kinetics of enzyme is influenced by the factors such as substrate concentration, enzyme quantity, temperature, $\mathrm{pH}$ value, solvent and immobilized material, and so on. Through the performance of enzyme catalyzed transesterification reaction and the chromatography analysis on reaction kinetics, the experimental operation, instrumental analysis and software use are mastered, the kinetic curves of enzyme are drawn, the change characters of the enzyme catalytic activity are found, and the catalytic activity and stability of lipase are thought by them. These research activities are to verify the effect of hydrophilic molecules in place of the water molecules to stabilize the enzyme protein, and so as to deepen knowing the enzyme catalysis mechanism and the kinetic characteristics.

Table 1. Situation of students in research project in the last three years

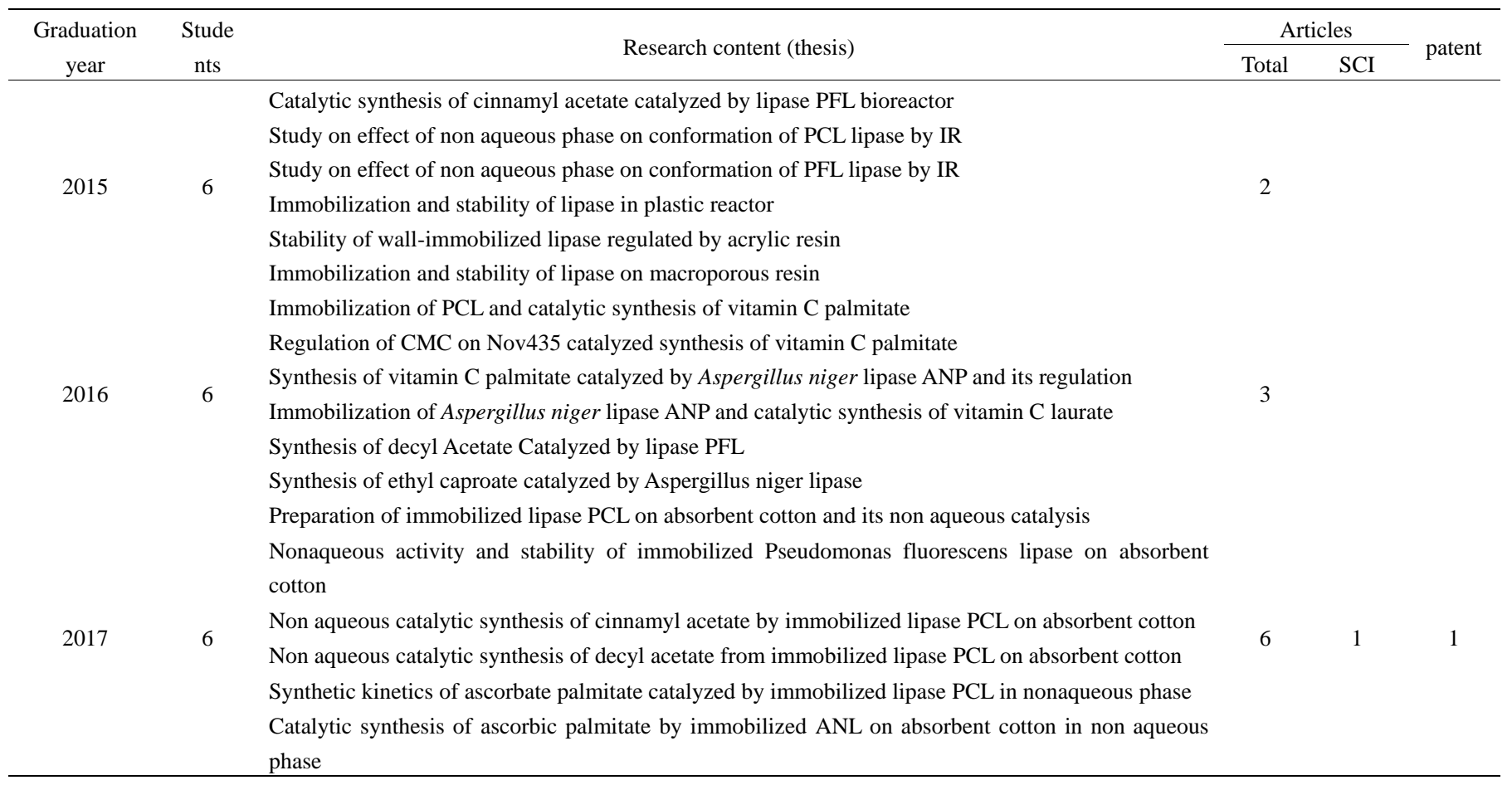




\section{Results}

\subsection{Summary of Typical Results}

The situation on students involved in the research project in this case are shown in Table 1. The students participated in the scientific research work, studied the work related to enzyme catalysis and enhanced the enzyme catalysis by enzyme immobilization. There are 3 Undergraduates' Innovation and Entrepreneurship Projects carried out by those participated in scientific research works of teachers. One is national level, one is municipal level and one is school level (Table 2). In the past 2015-2017 years, they have published 11 relevant research papers by the first author, including 1 SCI journal papers, 7 core journal papers, 2 general journal papers, 1 conference paper, and applied 1 invention patent. After nearly 3 years of demonstration for scientific research into teaching, 18 undergraduates have been guided into research projects and 18 thesis have been completed. It was obvious that not only biochemical course was better learned but also some considerable research results were obtained by them. And now, a novel national level project is applied and carried by another 5 students (Table 2).

Table 2. Summary of student related projects

\begin{tabular}{ccccc}
\hline Applied year & Students & Level & Title & Situation \\
\hline 2014 & 6 & National & Study on non aqueous stability of wall-immobilized PCL & Completed \\
2015 & 4 & Municipal & Study on immobilization of lipase on absorbent cotton & Completed \\
2016 & 3 & School & Enzymatic synthesis and isolation of vitamin C ester & Completed \\
2017 & 5 & National & Trial preparation and application of esterase reactor & Processing \\
\hline
\end{tabular}

\subsection{Enhanced Quality and Ability}

Through participating in scientific research projects, students can innovate their thinking and actively apply the projects of innovation and entrepreneurship. In the last three years, 6 students gave an idea stabilizing lipase with glass wall and hydrophilic molecules, and then applied the national scale project 'Study on non aqueous stability of the wall-immobilized Pseudomonas cepacia lipase', and published 4 core journal papers (Wang et al., 2015; Liu et al., 2015; Zhan et al., 2016; Ding et al., 2017). Another 4 students thought that absorbent cotton was a fine hydrophilic molecule stabilizing the enzyme protein, and applied the municipal level project 'Immobilization of lipase on absorbent cotton', and published 1 SCI journal paper (Wang et al., 2018), 2 core journal papers (Kang et al., 2017; Zhang et al., 2017) and 1 general journal paper (Zhou et al., 2018), and declared 1 invention patent (Cong, Kang, Wang, Zhang \& Zhou, 2016). And 3 students envisaged to prepare immobilized lipases to catalyze synthesis of vitamin $\mathrm{C}$ ester, and analyze and separate reaction products, and therefore applied the school level project 'Study on enzymatic synthesis and separation of vitamin $\mathrm{C}$ esters, and published 1 core journal article (Lv et al., 2017), 1 general journal paper (Xu et al., 2018) and 1 conference paper (Bi et al., 2017).

\section{Discussion}

\subsection{Improving Cognition of Course Content}

Through participating in scientific research projects, students' scientific thinking and practical ability were trained, and their cognitions on key and difficult contents were deepened. They are more aware of the fact that the essence of enzyme is protein, which is changeable in organic solvents, but its conformation can be stabilized through immobilization. It is recognized that the appropriate materials can be selected according to the catalytic mechanism of enzyme, and used to adjust its catalysis by enzyme immobilization method, which benefit to understand on the catalytic mechanism of enzyme. It is also recognized that the kinetics of enzyme catalysis follows certain rules, the enzyme kinetics curve can be obtained through enzyme catalyzed transesterification and chromatographic analysis, and some key factors affecting the enzyme catalytic effect are found in researches. Furthermore, the importance of scientific research is impressed. Scientific research can verify and discover scientific knowledge, improve the ability of innovative thinking and research ability, and be an effective way to make further progress.

\subsection{Scientific Arrangements Reducing Burden of Students}

Linking students' courses, scientific researches and graduation thesis can not only improve the course knowledge and cultivate the scientific research quality, but also expediently complete the graduation thesis and as a result reduce the burden of them. In other words, for students, it has achieved twice the result with half the effort. For that the ability of searching literature, designing research plans and writing papers cultivated in scientific 
research, is helpful for students to choose the research content of graduation thesis and carry out relevant work. The 3 years of practice has proved that the effect is very significant. 18 students not only successfully completed the design, research, writing and defense of graduation thesis, but also 11 students among them published their research papers by the first author, including 1 SCI papers, 7 core papers, 2 general journal papers and 1 conference papers (Table 1).

\section{Acknowledgements}

The work was supported by the fund of Modern Aqua-ecology and Health Aquaculture Innovation Team of Tianjin (TD13-5089), the Tianjin Aquatic Industry Technical System-Water Quality Control Position (ITTFRS2018015), the Undergraduates' Innovation and Entrepreneurship Project (201710061012) and the Open Fund of Tianjin Key Lab of Aquatic Ecology and Aquaculture (TJAE201502).

\section{References}

Bi, W.D., Xu, W.T., Cong, F.D., Lv, X., Zhang, S.L., Liu, L.Y., \& Yang, W. (2017). Synthesis of ascorbic palmitate L-catalyzed by immobilized Pseudomonas cepacia lipase. Shanghai, 2017 Third Biopharmaceutical Summit, 1-6.

Chen, Y.J. (2016). Rebalance of contradictions between teaching and scientific research from the perspective of undergraduate teaching audit assessment. Journal of Kunming University of Science and Technology (Social Science Edition), 16(4), 78-87.

Cong, F.D., Kang, J., Wang, X., Zhang, Y., \& Zhou, M.J. (2016). Preparation of absorbent cotton-immobilized lipase and application thereof [P]. 2016106384004.

Ding, J.Z., Cong, F.D., Zhan, M.R., Kang, J., Zhou, W.L., \& Xing, K.Z. (2017). Synthesis of decyl acetate catalyzed by immobilized Pseudomonas fluorescens lipase. China Food Additives, (3), 122-126.

Guo, P., Xu, L.P., \& Zhang, G.S. (2017). Research on the interactive mode of teaching and scientific research of remote sensing course in local university. Geospatical Information, 15(12), 115-116.

Kang, J., Wang, X., Zhang, Y., Zhou, M.J., Cong, F.D., \& Xing, K.Z. (2017). Nonaqueous activity and stability of Pseudomonas cepacia lipase immobilized on absorbent cotton fiber. Chinese Journal of Biochemistry and Molecular Biology, 33(4), 386-390.

Liu, Y.S., Hu, X.C., Cong, F.D., Wang, S.D., Wang, Y.L., Wang, S.S., .. Zhou, M.J. (2015). Immobilization of pseudomonas fluorescens lipase (PFL) and its catalysis in synthesis of cinnamyl acetate. China Food Additives, (6), 140-144.

Lv, X., Yu, W.Q., Guan, X., Zhou, X.Q., Bi, W.D., Zhang, S.L., \& Cong, F.D. (2017). CMC mediated lipase-catalyzed synthesis of L- ascorbyl palmitate. China Food Additives, (2), 70-74.

Wang, H.M., Zhao, W.Z., Wang, Y., \& Xu, J.F. (2017). Case Study and Analysis of Scientific Research into Teaching in Colleges and Universities. Future and Developmen, (4), 72-75.

Wang, S.D., Wang, S.S., Cong, F.D., Hu, X.C., Xing, K.Z., Wang, Y.Y., \& Zhang, Y. (2015). Polyacrylic resin mediated catalysis of Pseudomonas cepacia lipase. Food Science and Technology, 40(10), 211-215.

Wang, X., Wang, X.H., Cong, F.D., Xu, Y.L., Kang, J., Zhang, Y., ... Pan, H. (2018). Synthesis of cinnamyl acetate catalysed by highly reusable cotton-immobilized Pseudomonas fluorescens lipase. Biocatalysis and Biotransformation, 36(4), 332-339.

Wei, H.F., Jiang, H.Q., \& Liu, Q. (2017). Study on the Transformation in the Teaching of Pharmaceutical Research Achievements. Shandong Chemical Industry, 46(11), 151-152,155.

Wu, Z.Q., Li, M., \& Lu, L.W. (2017). Reflection on the transformation of scientific research achievements into teaching resources from the perspective of undergraduate teaching audit evaluation. Theory and Practice of Contemporary Education, 9(6), 105-107.

Xu, W.T., Bi, W.D., Cong, F.D., Yu, W.Q., Zhang, S.L., Yang, W., \& Luo, W. (2018). Immobilized Aspergillus niger lipase catalyzed synthesis of L-ascorbyl palmitate in nonaqueous medium. Chinese Journal of Bioprocess Engineering, 16(4), 36-39.

Yan, H.C., \& Zhang, S.F. (2015). The return of the essence of University Education -- Research into teaching, University Education, (9), 16-17.

Yu, Z.J., \& Chen, C.H. (2017). Study on flipped classroom teaching of biochemistry based on network teaching platform. Journal of East China University of Technology (Social Science Edition), 36(4), 398-400. 
Zhan, M.R., Ding, J.Z., Cong, F.D., Xing, K.Z., Zhou, W.L., \& Zhang, S.L. (2016). Exploring the regulation of synthesis of ethyl caproate catalyzed by Aspergillus niger Lipase. Liquor-Making Science \& Technology, (12), 28-30.

Zhang, Y., Zhou, M.J., Cong, F.D., Wang, X., Zhang, S.L., Liu, H.X., .. Yang, W. (2017). Synthesis of decyl aceate catalyzed by cotton-immobilized lipase PCL. China Food Additives, (12), 51-56.

Zhao, L., Zheng, X.K., Ma, L.G., Shi, S.L., Han, Y.G., \& An, N. (2016). The instructional design case of the enzyme for students majoring in chinese pharmacy. Chinese Medicine Modern Distance Education of China, 14(1), 18-19.

Zhou, M., Zhang, Y., Cong, F.D., Zhang, S.L., Liu, L.Y., \& Luo, W. (2018). Synthesis of cinnamyl acetate in an immobilized-lipase bioreactor. Journal of Tianjin Agricultural University, 25(1), 64-67, 80.

\section{Copyrights}

Copyright for this article is retained by the author(s), with first publication rights granted to the journal.

This is an open-access article distributed under the terms and conditions of the Creative Commons Attribution license (http://creativecommons.org/licenses/by/4.0/). 